\title{
Characterization of a Stress-Responsive Ankyrin Repeat-Containing Zinc Finger Protein of Capsicum annuum (CaKR1)
}

\author{
Eun Soo Seong ${ }^{1,2, \#}$, Doil Choi ${ }^{2,3, *}$, Hye Sun Cho ${ }^{2, \#}$, Chun Keum Lim $^{4}$, Hye Jeong Cho ${ }^{1}$ and Myeong-Hyeon Wang ${ }^{1, *}$ \\ ${ }^{1}$ School of Biotechnology, Kangwon National University, Chuncheon, Kangwon-do, 200-701, South Korea \\ ${ }^{2}$ Plant Genome Research Center, Korea Research Institute of Bioscience and Biotechnology, Taejeon 305-600, South Korea \\ ${ }^{3}$ Department of Plant Sciences, College of Agricultural and Life Sciences, Seoul National University, Seoul 151-742, South Korea \\ ${ }^{4}$ College of Agriculture and Life Sciences, Kangwon National University, Chuncheon, 200-701, South Korea
}

Received 30 May 2007, Accepted 16 July 2007

\begin{abstract}
We isolated many genes induced from pepper cDNA microarray data following their infection with the soybean pustule pathogen Xanthomonas axonopodis pv. glycines 8ra. A full-length cDNA clone of the Capsicum annuum ankyrin-repeat domain $\mathrm{C}_{3} \mathrm{H}_{1}$ zinc finger protein (CaKR1) was identified in a chili pepper using the expressed sequence tag (EST) database. The deduced amino acid sequence of CaKR1 showed a significant sequence similarity $(46 \%)$ to the ankyrin-repeat protein in very diverse family of proteins of Arabidopsis. The gene was induced in response to various biotic and abiotic stresses in the pepper leaves, as well as by an incompatible pathogen, such as salicylic acid (SA) and ethephon. CaKR1 expression was highest in the root and flower, and its expression was induced by treatment with agents such as $\mathrm{NaCl}$ and methyl viologen, as well as by cold stresses. These results showed that CaKR1 fusion with soluble, modified green fluorescent protein (smGFP) was localized to the cytosol in Arabidopsis protoplasts, suggesting that CaKR1 might be involved in responses to both biotic and abiotic stresses in pepper plants.
\end{abstract}

Keywords: Abiotic stress, biotic stress, CaKR1, methyl viologen, pepper plants

${ }^{\#}$ These authors are equally contributed to this work.

Abbreviations: AKR, Arabidopsis ankyrin repeat; AKRP, Arabidopsis ankyrin repeat protein; ANK, Ankyrin; smGFP, green fluorescent protein; SA, salicylic acid; CaKR1, Capsicum annuum ankyrinrepeat-domain $\mathrm{C}_{3} \mathrm{H}_{1}$ zinc finger protein; $\mathrm{PR}$, pathogenesis-related; $\mathrm{HR}$, hypersensitivity response; JA, jasmonic acid.

*To whom correspondence should be addressed.

Tel: 82-33-250-6486; Fax: 82-33-241-6480

E-mail: mhwang@kangwon.ac.kr (Wang, M.H)

Tel: 82-2-880-4568; Fax: 82-2-873-2056

E-mail: doil@snu.ac.kr (Choi, D.)

\section{Introduction}

Plants are subject to numerous biotic and abiotic stresses, including attacks by various pathogens and environment through their life cycle. To survive these stresses, plants have developed a diverse and complex set of defense mechanisms (Dixon and Lamb, 1990; Dangl and Jones, 2001). Plants respond by triggering specific signal transduction cascades that result in the induction of genes involved in the defense response and the production of antimicrobial compounds (Yang et al., 1997; La Camera et al., 2004). Salicylic acid (SA) and ethylene are important secondary signals in the plant defense response against pathogens (Ecker and Davis, 1987; Durner et al., 1997). Abscisic acid (ABA) is also involved in the regulation of defense-related signaling in response to biotic stresses (Mauchi-Mani and Mauch, 2005).

An ankyrin repeat-containing gene has been named AKR (Arabidopsis anKyrin Repeat), and the protein it encodes has been designated AKRP (Arabidopsis anKyrin Repeat Protein) (Zhang et al., 1992). The ankyrin (ANK) repeat is a 33-amino acid motif that appears 22 times in tandem in the $89 \mathrm{~K}$ domain of the human protein ankyrin (Lux et al., 1990). The proteins containing ANK repeats have determined the presence of 105 genes encoding and ANK repeats proteins in the other classes possess additional motifs such as transmembrane domains, kinase signatures, zinc or ring fingers (Becerra et al., 2004). The major role of plant ANK repeat proteins is related to signaling in defense (Cao et al., 1997) and development mechanisms (Li and Chye, 2004; Hemsley et al., 2005). A protein (EMB506) containing ANK repeats organized in tandem, and played a role for embryogenesis and proplastid differentiation (Despres et al., 2001). ANK repeats have been found in proteins functions, such as cell cycle regulation, mitochondria, cytoskeleton interactions, and signal transduction (Sedgwick and Smerdon, 1999). The Arabidopsis ANK repeatcontaining protein may be involved in the regulation of 
antioxidation metabolism by both disease resistance and stress responses (Yan et al., 2002).

In the present study, we isolated a Capsicum annuиm ankyrin-repeat domain $\mathrm{C}_{3} \mathrm{H}_{1}$ zinc finger protein, CaKR1, from chili pepper inoculated with Xanthomonas axonopodis pv. glycines 8ra (X.ag 8ra) (Hwang et al., 1992). Northern blot analyses revealed that the expression of CaKR1 was rapidly and preferentially induced during the HR of chili pepper to the incompatible interactions with the bacterial pathogens. CaKR1 is targeted to the cytosol of protoplasts from our experiments on cellular localization, providing that the role of CaKR1 is involved in the both biotic and abiotic stress responses in pepper.

\section{Materials and Methods}

Plant material and treatment. Chili pepper (Capsicum annuum) 'Bukang' seeds were cultured in MS (Murashige and Skoog) medium (MS salts including MS vitamins, 3\% sucrose, $0.8 \%$ agar, $\mathrm{pH}$ 5.8). The germinated plants were transferred to pots and kept in a growth chamber at $24^{\circ} \mathrm{C}$ for 4 weeks. The bacterial pathogen used for inoculation was $X$. axonopodis pv. glycines 8ra ( $X$. ag 8ra), a soy bean pustule pathogen (Hwang et al., 1992). Bacterial infiltration was accomplished by syringe infiltration of bacterial suspensions (approximately $4 \times 10^{8} \mathrm{cfu} / \mathrm{ml}$ ). The leaves were detached in a sterilized water solution containing $5 \mathrm{mM} \mathrm{SA}, 5 \mathrm{mM}$ ethephon and $100 \mu \mathrm{M}$ MeJA. They were placed in distilled water and kept in a $4^{\circ} \mathrm{C}$ cold chamber under dim light for $24 \mathrm{~h}$, and they were incubated in $0.25 \mathrm{M} \mathrm{NaCl}$ and $50 \mu \mathrm{M} \mathrm{MV}$ (Methyl Viologen) for $24 \mathrm{~h}$. The ABA stock solution was prepared by dissolving ABA in small aliquots of $1 \mathrm{~N} \mathrm{NaOH}$. The stock was diluted to $10^{-3} \mathrm{M}$ with distilled water and adjusted to $\mathrm{pH} 6.0$ with $0.1 \mathrm{~N} \mathrm{HCl} .10^{-4}$ and $10^{-5}$ $\mathrm{M}$ ABA solutions were concocted by further dilution. The ABA solutions were applied to detached leaves through their petiole.

Multiple amino acid sequence alignment. Multiple alignments of CaKR1 homologs were generated using http://us.expasy.org/tools. The accession numbers are: NP 200670 (Arabidopsis thaliana); ABE84364 (Medicago truncatula); XP469392 (Oryza sativa).

RNA Analyses. The total RNA was isolated from the pepper [subjected to $X$. ag 8ra, SA, MeJA (Methyl Jasmonic acid), ET, $\mathrm{NaCl}$, cold, MV, ABA or various tissues] (Chomczynski and Sacchi, 1987; Yi et al., 2004). Plant materials (1-1.5 g) were frozen in liquid nitrogen and homogenized in $10 \mathrm{ml}$ extraction buffer [ $4 \mathrm{M}$ guanidine isothiocyanate, $25 \mathrm{mM}$ sodium citrate at $\mathrm{pH} 7.0,0.55 \%$ (w/v) N-laurylsarcosine and $0.1 \mathrm{M}$ 2-mercaptoethanol]. A mixture of $2 \mathrm{M}$ sodium acetate $(\mathrm{pH} 4.0)$, water saturated phenol and chloroform-isoamylalcohol $(24: 1)$ was added to the homogenate. After centrifugation, the pellet was suspended in $2 \mathrm{M} \mathrm{LiCl}$ solution and incubated at $4^{\circ} \mathrm{C}$ for $18 \mathrm{~h}$. The total RNA concentration and purity were determined by spectrophotometer and staining of the ribosomal RNA with ethidium bromide, respectively. Equal quantities of the total RNA $(20 \mu \mathrm{g})$ were loaded into $1 \%$ agarose gel containing $7.4 \%$ formaldehyde. The RNA was transferred onto nylon membranes (Hybond $\mathrm{N}^{+}$, Amersham), then crosslinked under irradiation with UV light. To generate a CaKRl-specific probe, each coding sequence was PCR-amplified with two primers: (5'ATGTGTAGTGGTTCCGGGA-3' and 5'-ATGCACAATCTGCTC CTGCT-3') for CaKR1. Hybridization was performed overnight at $65^{\circ} \mathrm{C}$ in $5 \%$ dextran sulfate, $0.25 \mathrm{M}$ disodium phosphate $(\mathrm{pH} 7.2)$, $7 \%(\mathrm{w} / \mathrm{v})$ SDS and $1 \mathrm{mM}$ EDTA. After hybridization, the filter was washed twice with $2 \times \mathrm{SSC}$ and $0.1 \% \mathrm{SDS}$ for $10 \mathrm{~min}$ each at room temperature, and twice with $0.1 \times \mathrm{SSC}$ and $0.1 \%$ SDS for $5 \mathrm{~min}$ each at $65^{\circ} \mathrm{C}$.

Localization of CaKR1-smGFP fusion protein. CaKR1 was prepared by amplification using forward primer (5'-ACAGGATCC AAAGAGTAAAGAAGAACAGGATGTGTAGTGGTTCCGG-3') and reverse primer (5'-ATAGGATCCACCGCCTTCTAGCGTTTT CACCAGGGGGAACAAATG-3'). The C-terminus of the amplified $C a K R 1$ fragment was fused to the $\mathrm{N}$-terminal region of the smGFP (green fluorescent protein) expression vector (David and Vierstra, 1996), and the 35S-smGFP was constructed as a control. For transient expression, plasmid DNA ( $4 \mu \mathrm{g}$ each of p35S::CaKR1-sm GFP and p 35S::sm GFP) was introduced into the protoplast of Arabidopsis, and incubated for $12 \mathrm{~h}$ at $25^{\circ} \mathrm{C}$. The fusion construct was introduced into Arabidopsis protoplasts prepared from whole seedlings by the polyethylene glycol-mediated transformation procedure (Kang et al., 1998) for transient expression of smGFP:CaKR1. Fluorescence images were captured using an UV light fluorescence microscope (ZEISS, Axioskop, Germany) fitted with fluorescein isothiocyanate filters (excitation filter $520 \mathrm{~nm}$ and emission filter $488 \mathrm{~nm}$ ).

\section{Results and Discussion}

Sequence analysis of $\boldsymbol{C a K R}$. A pepper cDNA microarray was probed with RNA extracted from hot pepper leaves infected by $X$. ag 8ra to isolate pepper genes induced during the non-host bacterial pathogen HR. $X$. ag 8ra is not a pathogen of pepper, but induce the expression of a number of PR genes, as well as does occur an HR in pepper leaves (Lee et al., 2004), suggesting that 40 (out of 350 total ESTs) gene sequences were up-regulated more than 2-fold following $X$. $a g$ infiltration. One of the upregulated genes showed high sequence similarity to Arabidopsis ankyrin repeats protein that designated as a CaKRl. Sequence analysis of the $2.5 \mathrm{~kb}$ EST clone of CaKRl revealed that the cDNA was cloned into T vector and then sequenced. The complete sequence of CaKRI contained an open reading frame encoding a putative 597 amino acid protein. (Fig. 1). Nucleotide and protein database searches showed that CaKR1 has a 98 amino acid ANK domain that includes a 26 amino acid $\mathrm{C}_{3} \mathrm{H}_{1}$ zinc finger domain (Fig. 1). CaKR1 has a $46 \%$ and a $40 \%$ identity with the ANKdomain proteins of Arabidopsis (accession no. NP200670) and of rice (accession no. XP469392), respectively. By evaluating the sequence conservation, it became obvious that the terminal repeats of the arrays deviated from the general consensus and the same tendency has been observed in animal proteins (Bork, 1993). The conservation of the hydrophobic positions in Arabidopsis suggests that ANK repeats might 

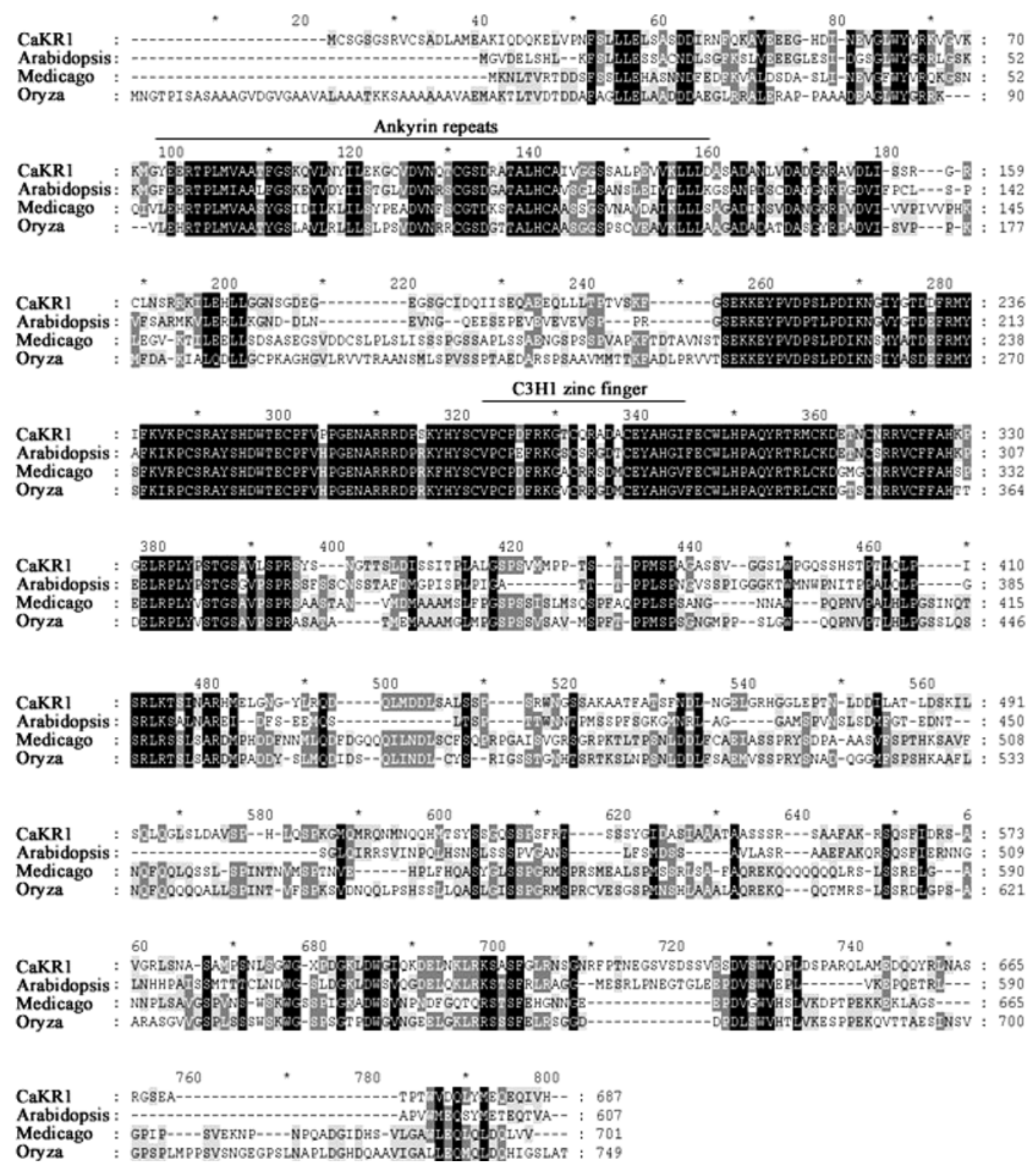

Fig. 1. Comparison of the deduced amino acid sequences of ankyrin-repeat-containing proteins having high sequence similarity to CaKR1. The black bar above the sequences represents the ankyrin repeats and the $\mathrm{C}_{3} \mathrm{H}_{1}$ zinc finger domain. Dashes indicate gaps used to optimize the alignment. The GenBank, DDBJ, EMBL, and NCBI accession numbers of the nucleotide sequences are as follows: DQ862464 (pepper cDNA [CaKR1]); NP200670 (Arabidopsis cDNA); ABE84364 (Medicargo cDNA), and XP469392 (Oryza sativa cDNA).

have similar functions in plants and animals. All the ANK repeats in Arabidopsis proteins were identified a total of 509 ANK repeats coded by 105 genes. Six genes of these proteins encode amino acids with ANK repeats and zinc finger domains. They are divided into two families (E1 and E2) (Becerra et al., 2004). Family E1 contains five genes coding proteins with two or three ANK repeats in the N-terminal region and one or two zinc-fingers in the central part of the protein (Becerra et al. 2004). Similar proteins are present in Oryza sativa and Medicago from our alignments (Fig. 1). The E2 family has an array of six ANK repeats. The functions of none of these proteins have been determined, but expression to Botrytis infection had analyzed. ZFAR1 encodes a protein harboring ankyrin repeat domains (AbuQamar et al. 2006).

Organ-specific expression of CaKR1. Northern blot analysis with RNA isolated from various tissues of pepper was performed with a CaKRl probe (Fig. 2). There was a signal in the root and flower tissues of non-stressed plants, but no signal in non-stressed leaves and stems. Some of the Ankyrin repeats genes seem to have more specific patterns of expression (Becerra et al. 2004). For example, EN14 and 


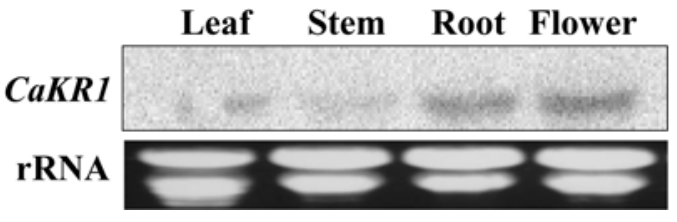

Fig. 2. Tissue RNA expression of the CaKRl gene. CaKRI RNA $(20 \mu \mathrm{g})$ levels were monitored in chili pepper leaves, stem, roots and flowers. The size of CaKRl is $2.1 \mathrm{~kb}$.

EN17 genes amplified only in roots and EN11 gene detected only in leaves. The pattern of expression of EN11 is consistent with ACD6 gene reported by Lu et al. (2005).

CaKR1 is induced by an incompatible pathogen. To determine if CaKR1 induction results from bacterial infection, the time course of gene transcript accumulation was analyzed by RNA blotting (Fig. 3A). The level of CaKRI transcripts increased following pathogen infection (Fig. 3A), indicating that CaKR1 is induced by incompatible pathogen interactions in leaf tissue of pepper. The Capsicum annum pathogen-related gene $(C a P R I)$ is also induced by various stresses in chili pepper (Kim et al., 2005). Interactions between incompatible pathogens and plants lead to rapid cell death that prevents the spread of harmful pathogens to neighboring cells (Heath, 2000). The HR response affects the levels of signal molecules, such as SA, jasmonic acid (JA), and ethylene (Reymond and Farmer, 1998). CaKR1 expression was strongly induced by treatment with SA and ethephon (an ethylene generator), and weakly induced by MeJA (Fig. 3B, C, and D). This result indicated that $\mathrm{CaKR} 1$ is expressed and functions earlier than that of CaPR-1 in response to SA exposure. Capsicum annuum Pin II (CaPIN II), the positive control for the MeJA treatment, significantly increased the expression level after $3 \mathrm{~h}$ of MeJA treatment.
CaAccoxidase, the positive control for the ethephon treatment (Chung et al., 2003), was induced after $6 \mathrm{~h}$ of ethephon treatment, indicating that $C a K R l$ transcription is regulated by incompatible pathogens as well as plant stress-related chemicals. The ACD6 protein, which contains an ANK-repeat domain, is an essential positive regulator of the defense response in Arabidopsis. The best-characterized ANK protein in plants, PR1/noninducible immunity 1 (NPR1/NIM1), is involved in SA-dependent disease resistance and in SAindependent resistance responses elicited by certain rootassociated bacteria (Pieterse et al., 1998).

CaKR1 is induced by abiotic stresses. Detached leaves of chili pepper plants were subjected to abiotic salt stress $(\mathrm{NaCl}$, $0.4 \mathrm{M}$ ). CaKRl transcript levels increased in response to a high-salt concentration (Fig. 4A) and were strongly induced by $24 \mathrm{~h}$ storage in a cold chamber (Fig. 4B). The Capsicum annuum dehydrin gene (Cadhn) is a marker gene that is regulated by abiotic stresses in chili pepper plants. Cadhn is responsive to ABA treatment, and its transcripts are abundant in green pepper fruits (Chung et al., 2003). There was a high level of expression up to $6 \mathrm{~h}$ after exposure to methyl viologen. Exposure of plants to abiotic stress factors, such as water deficit and a high concentration of salt, results in elevated ABA biosynthesis (Cohen and Bray, 1990), and increased ABA induces a number of genes (Bray, 1993). Expression of CaKR1 was also induced following treatment of chili pepper leaves with $100 \mu \mathrm{M}$ ABA (Fig. 4D). However, induction by ABA was lower than in the samples exposed to $\mathrm{NaCl}$, methyl viologen or cold (Fig. 4). The role of ABA was reported that it can positively or negatively regulate plant defense signaling pathways (Mauchi-Mani and Mauch, 2005), but the importance of $\mathrm{ABA}$ in plant resistance responses is still unknown.
(A)

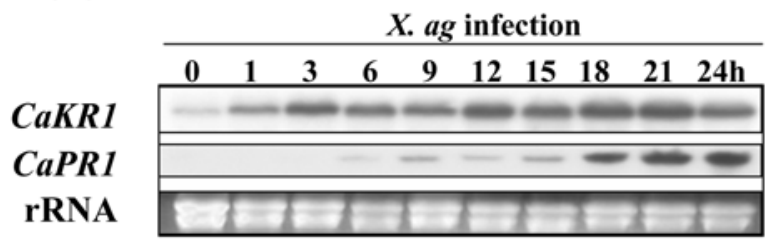

(C)

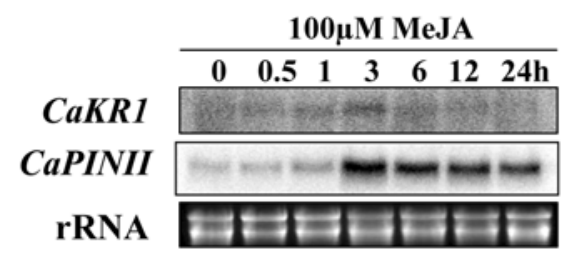

(B)

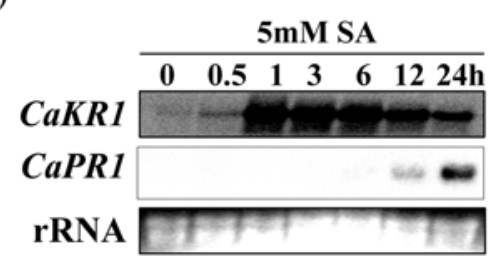

(D)

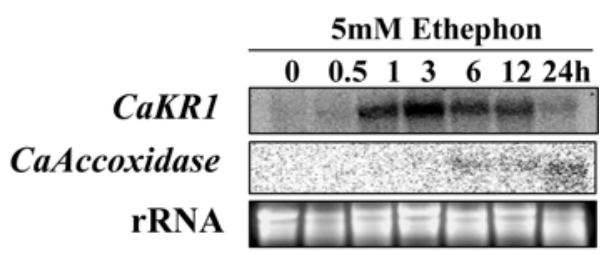

Fig. 3. Expression of CaKR1 mRNA in response to bacterial pathogens and chemicals. (A) Pepper leaves were infiltrated with $X$. axonopodis pv glycines 8ra (non-host pathogen). The CaPRI (Capsicum annuum Pathogenesis related protein l) gene was used as a positive control. (BD) Expression of CaKR1 mRNA (2.1 kb) following treatment with SA (salicylic acid), MJ (methyl jasmonic acid) or ethephon. CaPR1, CaPINII and CaAccoxidase used as positive control markers in chemical treatments of pepper. These results were assayed three times. 
(A)

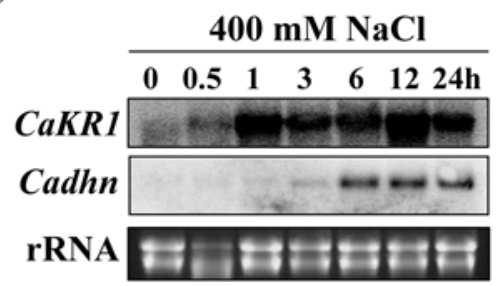

(C)

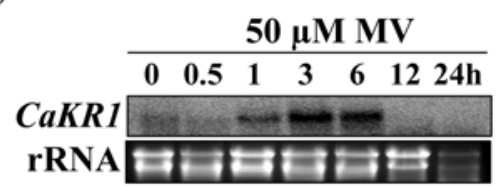

(B)

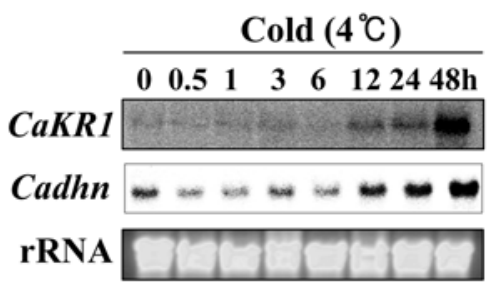

(D)

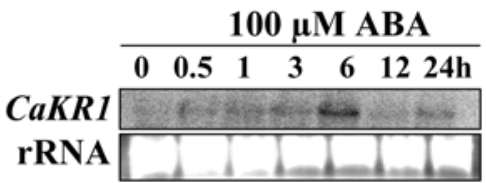

Fig. 4. Expression of CaKR1 mRNA in response to abiotic stress. The total RNA(A-D) was prepared from 2-month-old pepper plants transferred to a cold chamber and subjected to $0.4 \mathrm{M} \mathrm{NaCl}, 50 \mu \mathrm{M}$ methyl viologen, and $100 \mu \mathrm{M} \mathrm{ABA}$. Cadehydrin (Cadhn) served as positive control marker. The total RNA was extracted from the leaf tissue at the times indicated. The size of CaKR1 is $2.1 \mathrm{~kb}$.

The stress response in plants is evoked by the production of ROS (reactive oxygen species), which include $\mathrm{O}_{2}^{-}, \mathrm{H}_{2} \mathrm{O}_{2}$, and OH radical (Salin, 1988), and AKR2 can affect ROS production (Yan et al., 2002). The $\mathrm{OH}$ radical can be oxidized many cellular components and cause cellular damage (Cheeseman and Slater, 1993). Therefore, it is essential for plants to scavenge $\mathrm{H}_{2} \mathrm{O}_{2}$ from cells, but $\mathrm{H}_{2} \mathrm{O}_{2}$ serves as a messenger to trigger defense gene expression in host plant cells during pathogen infection (Levine et al., 1994). Accurate regulation in $\mathrm{H}_{2} \mathrm{O}_{2}$ production and destruction is critically important to the survival of plants, and it is governed by mechanisms that can involve antioxidant proteins and novel signal transduction pathways. The functions of ZFAR1, zinc finger protein harboring ankyrin repeats domain, was determined to increased salinity, ABA, and oxidative stress generated by paraquat (AbuQamar et al., 2006). Treatment with MV results in the formation of chloroplast-associated ROS species and is used to study general plant stress responses (Fujibe et al., 2003). Responses to various stresses, such as wounding, pathogens, cold, drought, salt, and highlight stress, were identified to the transcriptional level in a broad variety of stress response pathways. A model that integrates the multiple pathways involved in salt, drought, and cold responses have been published (Cheong et al., 2003).

CaKR1-smGFP fusion proteins are targeted to the cytosol of Arabidopsis protoplasts. To investigate the cellular location of CaKR1, we performed an in vivo targeting experiment employing CaKR1 fused to a modified form of smGFP (David and Vierstra, 1996). Protoplasts of Arabidopsis were transformed with the $35 \mathrm{~S}-\mathrm{CaKR} 1-\mathrm{smGFP}$ construct, or with 35S-smGFP alone (Fig. 5A). GFP fluorescence in the epidermal cells containing the 35S-CaKR1-smGFP construct was detected exclusively in the cytosol (Fig. 5B). NPR1 localizes to the nucleus and functions as a transcriptional coactivator to regulate the defense response (Fan and Dong, 2002).
(A)

\begin{tabular}{|c|c|c|}
\hline & 1 & $267 a a$ \\
\hline C1 & $5 \mathrm{~S}$ & CaKRI \\
\hline
\end{tabular}

(B)

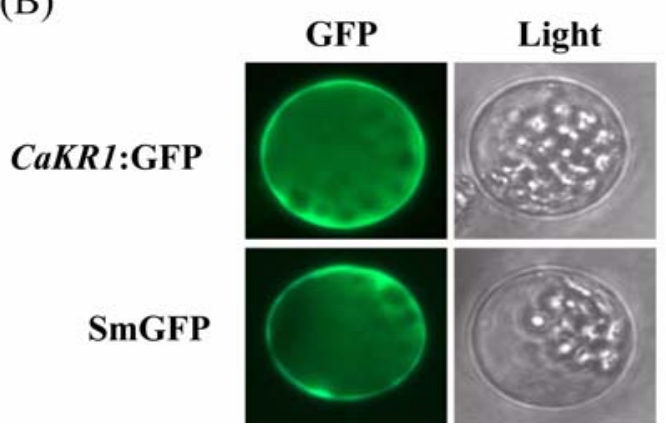

Fig. 5. The fusion construct CaKR1-smGFP and its subcellular localization. (A) CaKRl cDNA as a template with forward primer and reverse primer. The CaKRl coding region was fused in-frame to the N-terminus of the smGFP protein. The fusion protein is driven by the $35 \mathrm{~S} \mathrm{CaMV}$ promoter. (B) smGFP (lower panels) and CaKR1-smGFP (upper panels) were introduced into Arabidopsis protoplasts. Expression of the introduced genes was examined after $24 \mathrm{~h}$ using a fluorescence microscope. The results were assayed three times.

The LIANK protein containing five tandem ankyrin repeats and a RING zinc-finger domain possesses ubiquitin ligase activity in vitro (Huang et al., 2006). The primary function of ubiquitin ligase was the rapid degradation of proteins with abnormal conformations and of many regulatory proteins to facilitate in the regulation of their activities (Weissman, 2001). We expect that CaKR1 is possible role of E3 ligase activity, but none of it has been characterized in this study. In conclusions, plant ANK domain proteins are involved in signaling pathways (Lu et al., 2005), stress responses 
(Chinchilla et al., 2003), and plant defense (Kuhlmann, 2003). We identified a 98 amino acid region containing ANK repeats in CaKR1 isolated from chili pepper. The ANK repeat protein of Arabidopsis is transiently down-regulated transcriptionally by pathogen attack (Kuhlmann, 2003). Ankyrin1 homologous proteins function in pathogen defense (Kuhlmann, 2003). We found that the CaKRl transcript levels in pepper leaves increased in response to infection with an incompatible pathogen, $X$ ag 8ra, as well as to abiotic stresses. In this report, we show that CaKR1 is regulated by both abiotic and biotic stresses in pepper plants, suggesting that that it is involved in the signaling pathway. Understanding of how CaKR1 functions in plant defense and environmental stress responses should provide insights into plant disease resistance and abiotic stress tolerance.

Acknowledgment This research was supported by the grant from Research Institute of Agricultural Sciences at Kangwon National University.

\section{References}

AbuQamar, S., Chen, X., Dhawan, R., Bluhm, B., Salmeron, J., Lam, S., Dietrich, R. A. and Mengiste, T. (2006) Expression profiling and mutant analysis reveals complex regulatory networks involved in Arabidopsis response to Botrytis infection. Plant $J$. 48, 28-44.

Becerra, C., Jahrmann, T., Puigdomenech, P. and Vicient, C. M. (2004) Ankyrin repeat-containing proteins in Arabidopsis: characterization of a novel and abundant group of genes coding ankyrin-transmembrane proteins. Gene 340, 111-121.

Bork, P. (1993) Hundreds of ankyrin-like repeats in functionally diverse proteins: mobile modules that cross phyla horizontally? Proteins 17, 363-374.

Bray, E. A. (1993) Molecular responses to water deficit. Plant Physiol. 103, 1035-1040.

Cao, H., Glazebrook, J., Clarke, J. D., Volko, S. and Dong, X. (1997) The Arabidopsis NPRlgene that controls systemic acquired resistance encodes a novel protein containing ankyrin repeats. Cell 88, 57-63.

Cheeseman, K. H. and Slater, T. F. (1993) An introduction to free radical biochemistry. Br. Med. Bull. 49, 481-493.

Cheong, Y. H., Chang, H. S., Gupta, R., Wang, X., Zhu, X. and Luan, S. (2003) Transcriptional profiling reveals novel interactions between wounding, pathogen, abiotic stress, and hormonal responses in Arabidopsis. Plant Physiol. 129, 661-677.

Chinchilla, D., Merchan, F., Megias, M., Kondorosi, A., Sousa, C. and Crespi, M. (2003) Ankyrin protein kinases: a novel type of plant kinase gene whose expression is induced by osmotic stress in alfalfa. Plant Mol. Biol. 51, 555-566.

Chomczynski, P. and Sacchi, N. (1987) Single step method of RNA isolation by acid guanidium thiocyanate-phenol-chloroform extraction. Anal. Biochem. 162, 156-159.

Chung, E., Kim, S. Y., Yi, S. Y. and Choi, D. (2003) Capsicum annuum dehydrin, an osmotic-stress gene in chili pepper plants. Mol. Cells 15, 327-332.

Cohen, A. and Bray, E. A. (1990) Characterization of three mRNAs that accumulate in wilted tomato leaves in response to elevated levels of endogenous abscisic acid. Planta 182, 27-33.

Dangl, J. L. and Jones, J. D. G. (2001) Plant pathogens and integrated defense responses to infection. Nature 411, 826-833.

David, S. J. and Vierstra, R. D. (1996) Soluble derivatives of green fluorescent protein (GFP) for use in Arabidopsis thaliana. Weeds World 3, 43-48.

Despres, B., Delseny, M. and Devic, M. (2001) Partial complementation of embryo defective mutations: a general strategy to elucidate gene function. Plant J. 27, 149-159.

Dixon, R. A. and Lamb, C. J. (1990) Molecular communication in interactions between plants and microbial pathogens. Annu. Rev. Plant Physiol. Plant Mol. Biol. 41, 339-367.

Durner, J., Shah, J. and Klessig, D. F. (1997) Salicylic acid and disease resistance in plants. Trends Plant Sci. 2, 266-274.

Ecker, J. and Davis, R. W. (1987) Plant defense genes are regulated by ethylene. Proc. Natl. Acad. Sci. USA 84, 5202-5206.

Fan, W. and Dong, X. (2002) In vivo interaction between NPR1 and transcription factor TGA2 leads to salicylic acid-mediated gene activation in Arabidopsis. Plant Cell 14, 1377-1389.

Fujibe, T., Saii, H., Arakawa, K., Yabe, N., Takeuchi, Y. and Yamamoto, K. T. (2003) A methyl viologen-resistant mutant of Arabidopsis, which is allelic to ozone-sensitive rcd1, is tolerant to supplemental ultraviolet-B irradiation. Plant Physiol. 134, 275285.

Heath, M. C. (2000) Hypersensitive response-related death. Plant Mol. Biol. 44, 321-334.

Hemsley, P. A., Kemp, A. C. and Grierson, C. S. (2005) The TIP GROWTH DEFECTIVE1S-acyl transferase regulates plant cell growth in Arabidopsis. Plant Cell 17, 2554-2563.

Huang, J., Chen, F., Casino, C. D., Autino, A., Shen, M., Yuan, S., Peng J., Shi, H., Wang, C., Cresti, M. and Li, Y. (2006) An ankyrin repeat-containing protein, characterized as a ubiquitin ligase, is closely associated with membrane-enclosed organelles and required for pollen germination and pollen tube growth in lily. Plant Physiol. 140, 1374-1383.

Hwang, I., Lim, S. M. and Shaw, P. D. (1992) Cloning and characterization of pathogenecity genes from Xanthomonas campestris pv. Glycines. J. Bacteriol. 174, 1919-1923.

Kang, S. G., Jin, J. B., Piao, H. L., Pih, K. T., Jang, H. J., Lim, J. H. and Hwang, I. (1998) Molecular cloning of an Arabidopsis cDNA encoding a dynamin-like protein that is localized to plastids. Plant Mol. Biol. 38, 437-447.

Kim, S. Y., Kim, Y. C., Lee, J. H., Oh, S. K., Chung, E., Lee, S., Lee, Y. H., Choi, D. and Park, J. M. (2005) Identification of a CaRAV1 possessing an AP2/ERF and B3 DNA-binding domain from pepper leaves infected with Xanthomonas axonopodis pv. glycines 8ra by differential display. Biochim. Biophy. Acta 1729, 141-146.

Kuhlmann, M., Horvay, K., Strathmann, A., Heinekamp, T., Fischer, U., Bottner, S. and Droge-Laser, W. (2003) The alpha-helical D1 domain of the tobacco bZIP transcription factor BZI-1 interacts with the ankyrin-repeat protein ANK1 and is important for BZI-1 function, both in auxin signaling and pathogen response. J. Biol. Chem. 278, 8786-8794.

La Camera, S., Gouzerh, G., Dhondt, S., Hoffmann, L., Fritig, B., Legrand, M. and Heitz, T. (2004) Metabolic reprogramming in plant innate immunity: the contributions of phenylpropanoid and oxylipin pathways. Immunol. Rev. 198, 267-284.

Lee, S., Kim, S. Y., Chung, E., Joung, Y. H., Pai, H. S., Hur, C. G. 
and Choi, D. (2004) EST and microarray analyses of pathogenresponsive genes in hot pepper (Capsicum annuum L.) non-host resistance against soybean pustule pathogen (Xanthomonas axonopodis pv. glycines). Func. Integr. Genomic 4, 196-205.

Levine, A., Tenhaken, R., Dixon, R. and Lamb, C. (1994) $\mathrm{H}_{2} \mathrm{O}_{2}$ from the oxidative burst orchestrates the plant hypersensitive disease resistance response. Cell 79, 583-593.

Li, H. Y. and Chye, M. L. (2004) Arabidopsis acyl-coA-binding protein ACBP2 interacts with an ethylene-responsive elementbinding protein, AtEBP, via its ankyrin repeats. Plant Mol. Biol. 54, 233-243.

Lu, H., Liu, Y. and Greenberg, J. T. (2005) Structure-function analysis of the plasma membranelocalized Arabidopsis defense component ACD6. Plant J. 44, 798-809.

Lux, S. E., John, K. M. and Bennett, V. (1990) Analysis of cDNA for human erythrocyte ankyrin indicates a repeated structure with homology to tissue-differentiation and cell-cycle control proteins. Nature 344, 36-42.

Mauchi-Mani, B. and Mauch, F. (2005) The role of abscisic acid in plant-pathogen interactions. Curr. Opin. Plant Biol. 8, 409-414.

Pieterse, C. M., van Wees, S. C., van Pelt, J. A., Knoester, M., Laan, R., Gerrits, H., Weisbeek, P. J. and van Loon, L. C. (1998) A novel signaling pathway controlling induced systemic resistance in Arabidopsis. Plant Cell 10, 1571-1580.
Reymond, P. and Farmer, E. E. (1998) Jasmonate and salicylate as global signals for defense gene expression. Curr. Opin. Plant Biol. 1, 404-411.

Salin, M. A. (1988) Toxic oxygen species and protective systems of chloroplast. Physiol. Plant 72, 681-689.

Sedgwick, S. G. and Smerdon, S. J. (1999) The ankyrin repeat: a diversity of interactions on a common structural framework. Trends Biochem. Sci. 24, 311-316.

Weissman, A. M. (2001) Themes and variations on ubiquitination. Nat. Rev. Mol. Cell. Biol. 2, 169-178.

Yan, J., Wang, J. and Zhang, H. (2002) An ankyrin repeat-containing protein plays a role in both disease resistance and antioxidation metabolism. Plant J. 29, 193-202.

Yang, Y., Shah, J. and Klessig, D. F. (1997) Signal perception and transduction in plant defense responses. Genes Dev. 11, 16211639.

Yi, S. Y., Kim, J. H., Joung, Y. H., Lee, S., Kim, W. T., Yu, S. H. and Choi, D. (2004) The pepper transcription factor CaPF1 confers pathogen and freezing tolerance in Arabidopsis. Plant Physiol. 136, $2862-2874$.

Zhang, H., Scheirer, D. C., Fowle, W. H. and Goodmanav, H. M. (1992) Expression of antisense or sense RNA of an ankyrin repeat-containing gene blocks chloroplast differentiation in Arabidopsis. Plant Cell 4, 1575-1588. 